\title{
The Impact of Some Family Variables on the Dimension of Social Responsibility
}

\author{
Seham Ahmed Alazab ${ }^{a}$
}

\begin{abstract}
The current study discusses the social and psychological studies conducted on the concept of the social responsibility, as well as the symbolic interactive trend as a theoretical basis for interpretation; moreover, discussing the social responsibility in the light of family variables. The aim of this study is to investigate the family variables, including domicile, parents' education, their age, the type of work they do, family size, and family income. As to the social responsibility's dimensions for sample selected for this study; hence, it includes personal, ethical, national, environmental, health, and social responsibility. The current study adopted the descriptive approach along with a demographic data form and the social responsibility's scale. The sample selected consisted of 330 female students from various colleges within King Abdulaziz University. The results indicated that there was an impact on all the variables, thus such impact was in favor of those living in rural areas as to the ethical dimension and in favor of urban people as to the dimensions of accountability, parents' level of education, parents' seniority, working mothers, greater family size, and higher income.
\end{abstract}

\section{Keywords}

Personal responsibility, ethical responsibility, national responsibility, social responsibility, environmental, health responsibility

Social responsibility is among such vital issues concerned by human communities, as such reflects the standards of social advancement; in addition, it is not the responsibility of the individual only but the community in general, e.g. individuals, groups, public institutions, and private organizations. Furthermore, social responsibility teaches children accountability toward others in terms of extending individual services or social participation, cooperation, and self-denial where the community takes precedence (Badawi 2006: 100). Social responsibility is enhanced by the family through teaching children, in early age, the virtue of true words and acts, subsequently the family member grows up thus having such magnanimous behavior towards the community (Alkhawaledah 1987: 126). Moreover, self-accountability is developed through the years where the individual realizes the importance of ethical, national, and social responsibility, e.g., such attitude is learned and acquired. In light of the foregoing, the aim of this study is to investigate the family variables, e.g., domicile, parents' education, their age, the type of work they do, family size, and family income. As to the social responsibility's dimensions for sample selected for this study; hence, it includes personal, ethical, national, environmental, health, and social responsibility.

\footnotetext{
aKing Abdulaziz University, Jeddah, Saudi Arabia

\section{Correspondent Author:}

Seham Ahmed Alazab, Department of Sociology and Social Work, Faculty of Arts and Humanities, King Abdulaziz University, PO Box 42803, zip code 21551, Jeddah, Saudi Arabia
} 


\section{CONCEPTUAL AND THEORATICAL FRAMEWORK}

\section{The Concept of Social Responsibility}

By the fall of the second half of the past twentieth century, social responsibility shifted from being the responsibility of commercial and industrial firms in relation to environment protection, to be concerned also socially by studying numerous social and psychological variables. However, various definitions say that social responsibility is individual and group oriented and is morally binding within a given community (Aladel 1998: 15); furthermore, such binding attitude is in line with God's teachings that the individual is responsible for the prosperity of him/herself as well as the community (Zahran 1984: 229) thus (Othman 1986: 43) concurs with such belief. Nonetheless, others such as Alharthy (1995: 3) defined social responsibility as a self-motivation attitude, where the individual recognizes that he/she has a duty towards the community, where sociologists define it as a social consciousness that is reflected by the individual behavior, e.g. the quality interaction with the others, where the community's interests comes first (Alhassan 1999: 51-52). However, Alkharashi (2004) believed that social responsibility is a self-conscious attitude, where the individual recognizes that the community needs his/her efforts, giving as well as sacrifices. In this current study, social responsibility is defined, procedurally, as the role of each member within the community, where all take the interests of community first thus self-denial becomes conspicuous in words and actions based on religion belief and ethics, as well as national duty towards self, community, and environment.

\section{Social Responsibility in Light of Symbolic Interactive Approach}

Such approach, based on social and psychological considerations, studies social and personality background as the individual draws behavior and way of thinking from the community (Alkhawli 2000: 151). As a result, many researchers believe that the personality of the individual is developed according to social environment, hence the personality disorder is attributed to past experience survived during childhood. Therefore, sociologists believe that the role of the social impact is to create a balance between the individual wants and needs and the community requirements. In other words, the positive social impact maintains social structure through conveying values, custom, and traditions to the individual (Kutobkhanah 2006: 171).

Intimacy within the family plays important role in formation of the family member's personality thus interprets the reactions of the individual towards the various situations that occur within the community; moreover, interaction with others is not adequate by words but deeds (Alkhateeb 2003: 80). Moreover, people communicate through language and through communication, they can express their consent or rejection, thus through interaction, social responsibility prospers (Kutobkhanah 2006: 55).

Notably, Geroge Herbert Mead, prominent contributors to the social impact, was more concerned with the language as primary means for interaction (Alghazawi et al. 2000: 195). Such interest in language is based on Herbret's belief that individuals draw their personal standoffs from the opinions, judgments, and orientations of those around him/her including sentiments, feelings, and perceptions; thus personality is structured in combination with such traits learned from the family, colleagues, and friends' way of life including agreement, objection, appreciation, reward, and punishment imposed by parents. Accordingly, the individual realizes whither his/her behavior is acceptable, rejected, or satisfactory (Alomar 1997: 109).

The "self" principle is divided into two parts: the internal factor (I) and the external factor (Me). However, (I) is the positive, active, and creative part of the "self", where the passive part is the part that is 
formed from such situations encountered with others (James 2005: 70). In addition, James, believes that the social-self is the result of two principal factors: the internally psychological factor, which reflects the individual traits and aspects of his/her personality; and the social factor, which reflects the social structure surrounding the individual, so both factors form the social-self of the individual. However, the social roots are the gradual growth of the individual capabilities as of childhood, where such functional roles are assessed by others. Hence, the language is the means for communication among individuals as such impacts the individual as well as others (Alhassan 2005: 82).

Self-social responsibility, as Mead sees it, is based on language, meanings, and symbols acquired by the children from their parents as well as communication with social circles and the family, hence the individual acquires personality accordingly.

Charles Herton Cooley, in addition, is a pioneer in such approach, who dedicated many researches to exploring how the personality of the individual is acquired through focusing in depth on "the self", the magnitude of experience gained by the individual through social interaction, family, playmates, neighborhood, etc. (Alzaltini 2008: 101).

Cooley, also, studied the individual self through social mirror, which means that the individual imagines his/herself as conceived by others as a person not based on his/her body, e.g. behavior, thinking, relations, and standoffs, which means that he/she was judged by others (Alomar 1997: 112). Therefore, Cooley, sees how others imagine us based on three levels:

(1) We imagine as the way others imagine;

(2) We imagine how others assess us and conceive us after such assessment;

(3) We develop a sort of attitude, in light of others' judgment and assessment (Light Jr. and Keller 1975: 133).

The social factor, based on such perspective, is that we maintain the social structure as a whole by passing the values, standards, custom, and traditions of the community to the individuals taking into consideration the role of the family in formulating the behavior of the children, which reflects their personalities, understandings, expectations, and aspirations, as well as impacts their self-development, social and ethical values.

\section{Social Responsibility in Light of Some Family Variables}

Previous studies conducted in the area of social and behavioral sciences focused on the social responsibility issue and its relation with the ethical development including other variables, hence we learned accumulative knowledge and reference in such field. However, the studies conducted in the area of family and social responsibility variables with university female students still need more in-depth research. The results of previous studies conducted, showed that the focus was on the social responsibility's dimensions related to the parents, such as: the study of Gunnoe, Hetherington, and Reiss (1999), which focused on the impact of the parents' religious characteristics on the children, and the study conducted by Lämsä et al. (2008) on the impact of the business administration on the trends of both genders as to social responsibility, which revealed that females are more concerned with ethical, environmental, and social issues than males. However, the study conducted by Whitley and Yoder (2015) on the development of social responsibility and political participation in universities, revealed that educational and civil involvement has a positive impact on the social responsibility, while the study conducted by Helker and Wosnitza (2016) on the interaction between the students and the parents in relation to social responsibility terms, the students' motivations and achievements, has determined three types of responsibilities: responsibility as to the learning process, educational achievement, and creation of a supporting social network —and all of such elements 
are connected with the responsibility terms and the experience of the parents.

As to the impact of the domicile variable on the social responsibility, the study conducted by Alqahtani (1998) revealed that, there are differences as to the interest in social responsibility between urban and rural students. However, the result of Alqahtani's study does not agree with the study conducted by Mushref (2009), which confirmed that there are no differences attributed to the domicile variable among students in Islamic universities; and the study conducted by Ali (2001) on the location and its relation to the social responsibility among Jahzza universities' students as to the domicile variable. Interestingly, the study conducted by Scott and Šerek (2015) on the social responsibility of majority and minority of race people as to resovling social conflicts, indicated that the majority show more interest in participation than those minorities, not based on social standards' motivation only but also by self-motivation towards social responsibility.

As to the impact of the educational level variable, the study conducted by Alhathaly (2008), on terrorism phenomenon and its relation with social responsibility, including other variables, based on a selective sample of students from Makkah, revealed that there are differences among such students attributed to the parents' level of education, thus in favor of those having higher education; however, the result of this study differs with the results of the study conducted by Mushref (2009) on the ethical thinking and its relation with responsibility based on a sample of selective students from Jahazza univiestities, which found differences as to the father's elementary and preparatory education thus in favor of preparatory education, as well as differences among mothers with university education and father's elementary education in favor of the elementary education. Also, the study conducted by Abdulhameed, Salam, and Affify (1988) on the social responsibility and the Qatari youth trends as to labor issues, time, and public property, revealed a low degree of social responsibility as to time hence with advancement in the level of education; nonetheless, Alqahtani's (1998) study revealed that, there were not relationships between the education and social responsibility variable, as well as the value with high school students in the Taif Governorate. However, the study conducted by Alsaud (2004), on the role of the school in enhancing the sense of social responsibility, revealed no differences as to the parents' education, the degree of sense as to the social responsibility. Moreover, Alharthy's (1995) study revealed high sense of social responsibility and a positive relationship at all aspects and the age variable in favor of the older people. Furthermore, the study conducted by Alshalawi (2006) titled "Religious Observation and Social Responsibility and Some Demographic Variavles, a Univesity Students Sample”, revealed that there are differences, along with the study conducted by Cole and Stewar (1996) as to the political attitude and the social responsibility with women, which revealed that the most effective social responsibility is demonstrated by those who are in the middle of age. And the study conducted by Alluhayyani (2011) on the ethical thinking and its relationship with the social responsibility with Um Al-Qura University students, revealed that the social responsibility is impacted by the age in favor of the elderly.

As to the impact of the occupation variable, the study conducted by Alharthy (1995) on personal and social responsibility covering Saudis in the Western Province and its relationship with some of the variables, revealed that teachers, among others, scored the highest level of personal responsibility, while military people, psychologists, and sociologists scored high at all respects, e.g. national system, environmental, personal, and social responsibility.

However, as to the family size variable, the study conducted by Wentzel (1991) on the relationship between social competence and level of education during teenage, was evident that there is a correlation 
between social responsibility and the structure of the family; moreover, Qandeel (2003) proved that, there is a relationship between the family atmosphere and social responsibility, while Mushref (2009) differed with such conclusions thus attributed it to the family size variable based on the results drawn from Islamic University's student.

As to the family income's impact on the social responsibility variable, Mushref (2009) indicated that there were differences in the level of sense towards social responsibility between high- and low-income families, thus such differences were in favor of low-income families, and such conclusion is in line with the results of the study conducted by Bin Obied (2015) based on a sample of students from King Saudi University, that the family plays vital role as to high sense of social responsibility, thus depends on the family income variable hence in favor of lower income families. However, the study conducted by Hassan (1984) on elementary school children's sense of social responsibility, was evident that decisions to carry out social responsibility activities vary among the various income families, thus in favor of higher income families.

\section{Hypotheses}

(1) There is an indicative statistical impact of the family domicile variable on the social responsibility (components and levels) with university female students.

(2) There is an indicative statistical impact of the parents' education variable on the social responsibility (components and levels) with university female students.

(3) There is an indicative statistical impact of the parents' age variable on the social responsibility (components and levels) with university female students.

(4) There is an indicative statistical impact of the parents' profession variable on the social responsibility (components and levels) with university female students.

(5) There is an indicative statistical impact of the family size variable on the social responsibility (components and levels) with university female students.

(6) There is an indicative statistical impact of the family income variable on the social responsibility (components and levels) with university female students.

\section{Limitations}

Time limitations. The study was conducted during the months of May and June 2016.

Location limitations. The study involved a number of theoretical and scientific colleges within King Abdulaziz University (KAU), namely Literature and Humanities College, Home Economics College, and the Science College.

Human limitations. The study was limited to the sample selected, e.g. 330 female students; 110 female students from each college as hereinabove mentioned.

\section{METHODOLOGY}

The study adopted the descriptive approach, as such was capable of exploring the differences or the relationships among the variables as well as explaining the nature of such relationships, and to conduct comparisons as to the social responsibility's dimensions.

\section{Community and Sample}

The study adopted the vertical sample which was probable and applied on the selected sample, e.g., 330 female students as indicated herein earlier.

\section{Tools Used}

Firstly: Form of the demographic variables. Which depicts a number of closed questions on some of the family's variables related to social responsibility, e.g. family domicile, parents' education, parents' age, 
parents' profession, family size, and family income.

Secondly: Social responsibility's scale. Such scale was developed by Alharthy (1995), hence the researcher introduced fundamental amendments to such scale so as to suit the current study, based on a gradual scale, i.e. ALWAYS, SOMETIMES, NEVER $(3,2,1)$, thus a total of each dimension can be attained, as well as the totals of the scale. The scale, however, consists of 50 phrases distributed on five dimensions, i.e. personal accountability, ethical accountability, national accountability, individual responsibility towards the community, and environmental and health responsibility, i.e. 10 phrases for each dimension.

\section{Validity and Reliability}

The reliability was as per Coronbach's Alpha, at .730, hence was stable and high, so the first half reliability was at .502 and .636 for the second half, and the correlation between both halves was at .565, and the correlation after Bireman Brawn's correction at .722 was stable and high. The validity was based on the internal consistency, e.g. the relationship of each item and the total represented by such total-and all were at positive correlation coefficient .01 .

\section{The Variables}

Independent variables. Family domicile, parents' education, parents' age, parents' profession, family size, and family income.

Dependent variables. Total social responsibility and its five components, i.e. personal accountability, ethical accountability, national accountability, responsibility towards community, and environmental and health responsibility.

\section{Statistical Methods Used}

A number of forms were designed for hypothesis testing, including: Pearson Correlation for credibility, T-Test to determine differences as to the profession, ANOVA (Analysis of Variance) to determine the differences as to the remaining variables, and
Scheffe’s Test for comparison purposes.

\section{RESULTS \& INTERPRETATION}

The aim of current study is testing the credibility of such hypothesis adopted, and through statistical analysis, the following results are attained:

\section{The Impact of the Family Domicile Variable on Social Responsibility}

There is a statistical indicative difference as to the family domicile in relation to personal accountability, national accountability, environmental and health responsibility dimensions, and total degree at $\mathrm{T}-3.58$, $\mathrm{T}-5.31, \mathrm{~T}-5.43$, and $\mathrm{T}-5.47$, e.g. values are at .01, which means that there are differences among female students at urban and rual areas thus in favor of those living at urban areas. As to the ethical accountability, the value of test- $-\mathrm{T}-4.21$ is at .01 , which means that there are not differences as to the social responsibility variable. Accordingly, the first hypothesis is achieved in general as it is found that there is a difference as to the family domicile variable on four of the five sub-dimensions of social responsibility.

Moreover, such results concur with Alqahtani's (1998) study that there are differences in the sense of social responsibility between urban and rural students hence in favor of the rural students, as well as the study conducted by Scott and Šerek (2015) that confirmed the majority show readiness to participate willingly not by social standards that encourage participation; in addition, the study conducted by Lämsä et al. (2008) revealed that females are more ethically responsible. Moreover, Mushref's (2009) study indicated that there are not differences among the Islamic University attributed to the domicile variable, as well as Ali's (2001), which came to the same conclusion.

These researchers, however, interpret the results of the current study, e.g. there are not differences as to personal accountability, national accountablility, 
environmental and health responsibility - and the grand total, among those living in rural centers. The differences only exist in the ethical responsibility, hence in favor of those living in rural areas, where there is no difference as to responsibility towards the community.

Taking into account the pioneers of the interactive theory of social structure, which focuses on achieving balance between the individual wants and the community needs, such theory helps preserving the social structure as a whole through passing the values, standards, custom, and traditions from a generation to another. Hence, in order to understand the Saudi society in general, and the radical conservative rural community, which relies on regligion as a reference for values, behaviors, and way of life, it is acceptable that the individual behavior is determined by the family domicile, and that is why there are differences as to the ethical responsibility within those living in rural areas. At the same time, the other responsibilities that depend on wider area of self-prove and participation are in favor of those female students living in urban center (Kutobkhanah 2006: 171).

\section{The Impact of the Parents' Education on the Extent of Social Responsibility}

It was clear, through ANOVA, that the parents' educational level, specifically the father's education, had an impact on the personal accountability and national accountability dimensions, at 3.75 and 5.96, and the values were at .05 ; in addtion, there was a difference as to the ethical responsibility-the individual responsibility towards the community-in relation to environment and health, at 9.05, 7.70, 7.37, and 12.9 for the dimensions mentioned, and all the values were at .01 .

The impact as to the mother's level of education as to the sense of ethical responsibility and the individual responsibility towards the community, the grand total of the variable was at 4.27 and 4.40 for both dimensions, and the values were at .05 .
To understand the differences among the sample members as to the parents variable, the researcher used Scheffe's Test for dimensional comparison for each score achieved by each member, e.g. illiterate, below average, average, high school, university or higher studies' individual, which were as follows:

There were differences at .05 among above average education and university and higher education individuals, as to the personal accountability, hence the difference was in favor of those females whose parents had university education and above, which meant increased sense of social responsibility.

There were differences at .05 among those who attained university education and above and those who attained below average education (intermediate and high school) as to the ethical responsibility dimension, and such differences were in favor of those female students whose parents achieved university education and above.

There were differences at .05 among those who attained university education and above and those who attained below average education (intermediate and high school) as to the national accountability dimension, and such differences were in favor of those female students whose parents achieved university education and above.

There were differences at .05 among those who attained university education and above and those who attained below average education (intermediate and high school) as to the community accountability dimension, and such differences were in favor of those female students whose parents achieved university education and above than those whose parents' education was below average, average, or high school.

As to the total score of social responsibility, there were differences at .01 among those who attained university education and above and all other categories not educated, below average, average, or high school, and such differences were in favor of those female students whose parents were not educated. Thus, such results indicate that those 
students whose parents have university education and above are more socially responsibility than those whose parents' education is below average, average, or high school.

However, there were differences at .05 among those whose mothers were educated as well as those whose mothers were not educated as to ethical accountability and the individual sense towards the community dimensions, which meant that, those whose mothers attained university education and above were more socially responsible than those whose mothers had no education.

Accordingly, the results of this current study confirm and achieve totally the second hypothesis as to the fathers' various levels of education, and achieve partially as to mothers, where differences relate to two of the five dimensions of social responsibility and total scores as per the scale adopted.

These findings, however, are in line with the study of Alhathaly (2008) which confirmed the existence of differences among the levels of sense towards social responsibility, depending on the education of the family head, and such differences were in favor of those who attained higher education; moreover, Mushref (2009) concluded that there are differences among the levels of sense towards social responsibilty based on mother's elementary education, as well as the study conducted by Whitley and Yoder (2015) which stated that association of the individual with educated or uneducated friendship circles plays vital role in determining the extend of sense towards social responsibility, and the study conducted by Helker and Wosnitza (2016) which stated that attitude towards social repsonbility is connected to the extent of the parents' experience, thus such conclusion differed with the result of the study conducted by Alqahtani (1998) as well as Alsaud (2004), which both confirmed irrelevance of the sense of social responsibility with the educational level of the parents.

Researcher of this study, however, believes strongly based on the results that there are differences among the female students as to all the sub-dimensions of social responsibility and the grand total in favor of those whose parents attain university education and above, as the lower is the education of the parents, the lower is the sense of social responsibility. Moreover, it once said by Mead that self-realization comes through the various milestones, situations, and circumstances survived by the individual, combined with such experiences drawn from family and social interactions, where finally the individual realizes his/her behavior, e.g. it is acceptable, rejected, or unsatisfactory (Alomar 1997: 109).

\section{The Parents' Age Variable as to Extent of Social Responsibility}

As per the ANOVA results, there is an impact of the father's social responsibility totally and its sub-components as to the ethical accountability. The $\mathrm{F}$ was at 4.77, which was indicative at .05; however, there was no impact as to the mother's age and the other dimensions as to the social responsibility.

In order to determine the differences, using Scheffe's Test, as to the father's age variable (less than 40 years, from 40 to 50 , and $50+$ years), it was clear that there was an impact at .05 in favor of less than 40 years and 40 to 50 years, as well as among $40+$ and 50 years old, thus in favor of older age category.

Accordingly, the study achieved the third hypothesis partially as to the fathers, e.g. the older father's age had an impact on the ethical accountability deminsion, thus there was no impact on the other sub-deminsins as to the social responsibility; furthermore, there was no impact from the mother's side on the other five sub-deminsions as to the social responsibility.

Such conclusion is in line with Alharthy (1995) who confirmed that there is a positive correlation relationship among all aspects of the social 
responsibility and the age variable, as well as the study conducted by Alshalawi (2006) which confirmed differences based on the age variable of the sample, thus in favor of the older individuals. However, these findings differed from the results of the study conducted by Cole and Stewar (1996) which indicated that those who are in their middle of age are more socially responsible, in addition to the Alluhayyani (2011) who said that the older are more socially responsible.

This result can be attributed to the impact of the parents' age (50+ years old) as to the ethical accountability dimension. Also it is worth mentioning that older Saudis survived a low economy era, where life was not easy but the new generation survives the prosperity of the oil economy. Hence, it is not easy to motivate the new generation. Accrodingly, Mead and Alhassan (2005: 82) agreed that the personal traits of the individual and the social factor are the elements that form the social responsibility-the author thus motivates the individual to be more socially responsible.

\section{The Parents' Profession Variable as to the Extent of Social Responsibility}

As per the ANOVA results, there is not an impact of the father's profesion totally and its sub-components as to the social responsibility. Moreover, there is not an impact of the mother's profession as to the individual sense of responsibility towards the community. The $\mathrm{F}$ value was at 3.50 which was indicative at .05 , and such variable had no impact on the other sub-dimensions of the social responsiblity.

In order to determine the differences, using Scheffe's Test, as to the mother's profession variable (housewife, retired or working mother), it was clear that there was an impact at .05 in favor of the working mothers as to the sense of the individual towards social responsibility.

Accordingly, the study achieved the fourth hypothesis partially as to the ethical accountability deminsion, thus there was not an impact on the other sub-deminsins as to the social responsibility; furthermore, there was no impact from the father's side on the other five sub-deminsions as to social responsibility.

Such conclusion is in line with Alharthy (1995), e.g. the profession impacts greatly thus differs as to its dimensions, thus the impact involves the dimensions of personal accountability, national accountability, environment and the total score of social responsibility.

Such findings can be attributed to the fact that individuals whose mothers work are more socially responsible as the working mother distributes her day-to-day responsibilities to her sons and daughters; moreover, most working mothers are educated and aware of the importance of their family members, assuming more responsibilities and having a positive attitude towards social responsibility.

This is in line with Cooley, who believes that the extent of the family's awareness, playmates, and neighbors nourishes social responsibility among the individuals. Therefore, the family and the social environment are connected so as to cultivate better sense of social responsibility (Alzaltini 2008: 101).

\section{The Family Size Variable as to the Extent of Social Responsibility}

As per the ANOVA results, there is not an impact of the family size totally and its sub-components as to the social responsibility, but there is an impact of the family size on the individual sense of responsibility towards the community. The $\mathrm{F}$ value was at 3.11 which was indicative at .05 , and such variable had no impact on the other sub-dimensions of the social responsiblity.

In order to determine the differences, using Scheffe's Test, as to the mother's profession variable (less than four members, 4-6 member, and six members above), it was clear that there was an impact at .05 in favor of families of four members and six members, thus in favor of large families as to the 
dimension of the individual's sense towards the community.

Accordingly, the study achieved the fifth hypothesis partially as there were differences among the sample's members as to the family's size; however, there was no impact of such variable on the other sub-dimensions of social responsibility.

These findings are in line with Wentzel (1991) that confirmed that there is a correlation between social responsibility and the structure of the family; however, Qandeel (2003) stated that there are no differences among the Islamic University students attributed to the family size variable.

Such findings can be attributed to the fact that large size families nourish better sense of social responsibility as the individual personality is better formed as of childhood. However, Cooley stated that the person sees him/herself the way other sees him/her and his/her action is judged by other (Alomar 1997: 112).

\section{The Family's Income Variable as to the Extent of Social Responsility}

As per the ANOVA results, there is not an impact of the family income totally and its sub-components as to the social responsibility, but there is an impact of the family size on the individual sense of responsibility towards the community. The $\mathrm{F}$ value was at 3.69 which was indicative at .05 , and such variable had no impact on the other sub-dimensions of the social responsibility.

In order to determine the differences, using Scheffe's Test, as to the mother's profession variable (less than 5,000 Saudi Riyals, SR 5,000 to SR 10,000, SR 10,001 to SR 15,000 , SR $15,000+$ ), it was clear that there was an impact at .05 in favor of families of four members and six members, thus in favor of income of bigger families as to the dimension of the individual sense towards the community.

Accordingly, the study achieved the sixth hypothesis partially as there were differences among the sample's members as to the family's income; however, there was no impact of such variable on the other sub-dimensions of social responsibility.

These conclusions are in line with Hassan (1984) that confirmed responsibilities are in parallel with the income of the family, e.g. the more income means the more responsibilities, thus such results differ from the results of the study conducted by Mushref (2009), where it is in favor of the lower income families, as well as the study conducted by Bin Obied (2015) that came up with the same conclusion of Mushref's.

These findings can be attributed to the fact that families with larger income can contribute more to the social responsibility activities, as well as extending help to others, where in return they gain stronger social status and good reputation within the community. moreover, business families are ethically and socially responsible due to their financial capability thus the community expects them to contribute and to participate more than any other segment within the community. hence, as Cooley said, we imagine ourselves as the way others look at and judge us through our actions (Light Jr. and Keller 1975: 113).

\section{CONCULSIONS}

(1) There is an impact related to the family domicile variable as to "personal accountability, national accountability, environmental and health responsibility" in favor of those living in urban centers, and an impact as to the "eithical accountability" in favor of those living in rural areas, thus there is no impact as to the dimension of the "individual responsibility towards the community".

(2) There is an impact related to the father's education variable on all dimensions of social responsibility, thus there is no impact from the mother's side as to the dimensions of "ethical accountability and the individual responsibility towards the community" in favor of fathers of higher education. 
(3) There is an impact related to the father's age variable as to ethical accountability in favor of those older fathers, thus there is no impact of such variable on the other sub-dimensions, and there is no impact of the mother's age variable on any of the five sub-dimesions as to social responsibility.

(4) There is an impact related to the mother's profession variable as to ethical accountability in favor of working mothers, thus there is no impact of such variable on the other sub-dimensions, and there is no impact of the father's profession variable on any of the five sub-dimesions as to social responsibility.

(5) There is an impact related to the family size variable as to "individual responsibility towards the community" in favor of larger families, thus there is no impact of such variable on the other sub-dimensions of social responsibility.

(6) There is an impact related to the family income variable as to "ethical accountability" in favor of higher income families, thus there is no impact of such variable on the other sub-dimensions of social responsibility.

\section{Recommendations}

Based on the results of the current study, the researcher proposes the following recommendations:

(1) To enhance the awareness of the parents as to their role in boosting social responsibility, especially ethical accountability of those living in urban centers, and boosting the individual participation within the community for those living in rural areas.

(2) Parents, regardless of the level of education especially low education, have to understand the social responsibility's dimensions and the importance of emphasizing such elements in their sons as of childhood.

(3) Launching of awareness programs and training courses, for parents of all ages especially the younger, on the social responsibility dimensions and imporantce to the community.

(4) Activiation of districts' clubs so as to hold various social responsibility activities that involve parents of all professions, especially non-working mothers.

(5) Dissemination of social responsibility culture among the families especially the small size families, to encourage more contribution, participation, and social integration in such manner serving the community in all aspects.

(6) Enhancement of social responsibility foundations by rectifying the understanding of social responsibility, especially the emphasis on those able to contribute and participate effectively.

(7) Activiation of the universities' role in community service through well-tailored programs and seminars as well as voluntary work so as to enable female students to contribute effectively.

(8) To conduct more research and social studies on social responsibility in light of the social changes by employing qualified cadres and various effective theories.

\section{References}

Abdulhameed, G., A. Salam, and M. A. Affify. 1988. The Relationship Between Social Responsibility and the Qatari Youth-Time, Work and Public Property. Qatar: Qatar University.

Aladel, A. A. 1998. "The Ability of Trouble-Shooting and Its Relationship With Social Intellegenc." The Education College Magazine, 22, Cairo.

Alghazawi, F. S., A. Khazaelah, M. Omar, N. Albanawi, and J. Altaher. 2000. Introdduction to Sociology. 2nd ed. Amman: Dar Alshorouq.

Alharthy, Z. H. 1995. Personal Social Responsibility, a Saudi Youth Sample, and Its Relation With Some Variables. Qatar: Qatar University, Research Center.

Alhassan, E. M. 1999. The Role of Arab Women in Social Responsbility Enhancement. Cairo: Dar Wael.

_ _ 2005. Advance Socology Theories-Analyticcal Studies. Cairo: Dar Quba.

Alhathaly, N. S. 2008. "Terrorism Phenomenon and Its Relation to Social Responsibility, a Makka High School Students Sample.” Master thesis, Um Al-Qura University, Saudi Arabia.

Ali, N. M. 2001. "Demography and Its Relation With Social 
Responsibility, a Ghazza University Students Sample.” Unpublished master thesis, Islamic University, Palestine.

Alkharashi, W. A. 2004. "The Role of Students Activities in the Development of Social Responsibiity, a University Students Sample.” Unpublished master thesis, King Saudi University, Saudi Arabia.

Alkhateeb, S. A. 2003. Overview on Modern Sociology. Riyadh: Alshagri Library.

Alkhawaledah, M. M. 1987. "The Concept of Responsibility, a Jordanian Youth Sample, and a Call to Include Responsibility in School Curriculum.” Arab Humanitarian Science Magazine 26:124-147. Kuwait.

Alkhawli, S. 2000. Family and Family Life. Cairo: Dar Alma'arefah, Aljama'eyah.

Alluhayyani, A. S. 2011. "Ethical Thinking and Its Relation With Social Responsibiity, in Light of Academic Changes, a University Students Sample.” Unpublished master thesis, Um Al-Qura University, Makkah.

Alomar, M. 1997. Modern Theories of Socology. Amman: Dar Alshorouq.

Alqahtani, M. G. 1998. "Social Responsibility and Its Relation With Values and Variables, a Taif High School Students Sample." Unpublished master thesis, Um Al-Qura University, Makkah.

Alsaud, M. A. 2004. "The Role of School in the Development of Social Responsibility, a Public High School Students Sample.” Master thesis, King Saud University, Riyadh, Saudi Arabia.

Alshalawi, A. M. 2006. "Religious Observation and Social Responsibility and Some Demographic Variavles, a Univesity Students Sample.” Unpublished master thesis, Um Al-Qura University, Makkah.

Alzaltini, M. F. 2008. Techniques of Family Social Development and Motivation of School Achievement. Cairo: Dar Quba.

Badawi, S. M. 2006. "Parental Treatment as Seen by Sons and Its Relations to Carrying out Social Responsibility.” Unpublished PhD thesis, Ain Shams University, Cairo.

Bin Obied, H. N. 2015. "The Role of the Family in the Development of Social Responsibility, a University Students Sample.” Master thesis, King Saudi University, Saudi Arabia.

Cole, E. R. and A. J. Stewar. 1996. "Meanings of Political Participation Among Black and White Women: Political Identity and Social Responsibility.” Journal of Personality and Psychology 71(1):130-140.

Gunnoe, M. L., E. M. Hetherington, and D. Reiss. 1999. "Parental Religiosity, Parenting Style, and Adolescent Social Responsibility.” The Journal of Early Adolescence
19(2):199-225.

Hassan, N. 1984. "Decision-Making and Social Responsibility, an Elementary Students Sample.” Unpublished master thesis, Taibah University, Saudi Arabia.

Helker, K. and M. Wosnitza. 2016. “The Interplay of Students' and Parents' Responsibility Judgements in the School Context and Their Associations With Student Motivation and Achievement.” International Journal of Educational Research 76:34-49.

James, M. H. 2005. Sociology: A Down-to-Earth Approach. 7th ed. New York: Better World Books.

Kutobkhanah, I. E. 2006. The Basics of Sociology. 2nd ed. Jeddah: Khawarizm Library.

Lämsä, A. M., M. Vehkaperä, T. Puttonen, and H. L. Pesonen. 2008. "Effect of Business Education on Women and Men Students' Attitudes on Corporate Responsibility in Society.” Journal of Business Ethics 82(1):45-58.

Light Jr., D. and S. Keller. 1975. Sociology. 2nd ed. New York: Alfred A. Knopf.

Mushref, M. M. 2009. "Ethical Thinking and Its Relation With Social Responsibilty, a Ghazza University Students Sample.” Master thesis, Islamic University, Palestine.

Othman, O. S. 1986. Social Responsibility and Social Islamic Personality. Research Center, Catary.

Qandeel, S. M. 2003. "The Family Environment as Seen by the Sons, a Cairo Elementary School Sample.” Master thesis, Ain Shams University, Cairo.

Scott, Z. and J. Šerek. 2015. "Ethnic Majority and Minority Youths' Ascription of Responsibility for Solving Current Social Issues Links to Civic Participation.” Journal of Adolescent Research 30(2):180-212.

Wentzel, K. R. 1991. "Social Competence at School: Relation Between Social Responsibility and Academic Achievement." Preview of Educational Research 61(1):1-24.

Whitley, C. T. and S. D. Yoder. 2015. “Developing Social Responsibility and Political Engagement: Assessing the Aggregate Impacts of University Civic Engagement on Associated Attitudes and Behaviors.” Education, Citizenship and Social Justice 10(3):217-233.

Zahran, H. 1984. Social Psycology. 5th ed. Cairo: Alam Alkotub.

\section{Bio}

Seham Ahmed Alazab, Ph.D., associate porfessor, Sociology \& Social Work, King Abdulaziz University, Jeddah, Saudi Arabia; research field: sociology. 